OPEN ACCESS

Edited by:

Wanjun Chen,

National Institutes of Health (NIH),

United States

Reviewed by:

Francesco De Francesco,

Azienda Ospedaliero Universitaria

Ospedali Riuniti, Italy

Takeo Mukai,

The University of Tokyo, Japan

*Correspondence:

Fuling Zhou

zhoufuling@whu.edu.cn

${ }^{\dagger}$ These authors have contributed equally to this work

Specialty section:

This article was submitted to

Stem Cell Research,

a section of the journal

Frontiers in Cell and Developmental

Biology

Received: 06 June 2020

Accepted: 08 April 2021

Published: 03 May 2021

Citation:

Shang Y, Guan H and Zhou F

(2021) Biological Characteristics

of Umbilical Cord Mesenchymal Stem

Cells and Its Therapeutic Potential

for Hematological Disorders.

Front. Cell Dev. Biol. 9:570179.

doi: 10.3389/fcell.2021.570179

\section{Biological Characteristics of Umbilical Cord Mesenchymal Stem Cells and Its Therapeutic Potential for Hematological Disorders}

\author{
Yufeng Shang ${ }^{\dagger}$, Haotong Guant and Fuling Zhou* \\ Department of Hematology, Zhongnan Hospital of Wuhan University, Wuhan, China
}

Umbilical cord mesenchymal stem cells (UC-MSCs) are a class of multifunctional stem cells isolated and cultured from umbilical cord. They possessed the characteristics of highly self-renewal, multi-directional differentiation potential and low immunogenicity. Its application in the field of tissue engineering and gene therapy has achieved a series of results. Recent studies have confirmed their characteristics of inhibiting tumor cell proliferation and migration to nest of cancer. The ability of UC-MSCs to support hematopoietic microenvironment and suppress immune system suggests that they can improve engraftment after hematopoietic stem cell transplantation, which shows great potential in treatment of hematologic diseases. This review will focus on the latest advances in biological characteristics and mechanism of UC-MSCs in treatment of hematological diseases.

\footnotetext{
Keywords: umbilical cord blood, mesenchymal stem cells, hematologic diseases, immunoregulation, hematopoietic microenvironment
}

\section{INTRODUCTION}

Mesenchymal stem cells (MSCs) are multipotent stem cells that originate in mesoderm at early development. MSCs were first discovered in bone marrow and later confirmed to be isolated from a variety of human tissues, such as adipose tissue, nervous tissue, umbilical cord and amniotic fluid (Kobolak et al., 2016; Zhan et al., 2019). Bone marrow MSCs (BM-MSCs) is extremely low while there is a high possibility of virus contamination. Moreover, the number of stem cells, the ability to expand and differentiate significantly decreased with age, which limits their clinical application (Kern et al., 2006). Subsequent studies have shown that human umbilical cords contain large amounts of MSCs (Kern et al., 2006). Traditionally, umbilical cord tissue is regarded as a waste product after birth, so there is no ethical controversy to isolate MSCs from umbilical cord tissue compared with obtaining MSCs from bone marrow. The morphological, immunophenotype, proliferation, multi-directional differentiation and the ability to promote differentiation of hematopoietic stem cells (HSCs) in UC-MSCs are mostly similar to those BMMSCs (Thaweesapphithak et al., 2019), but UC-MSCs have higher proliferative capacity and lower human leukocyte antigen (HLA)-ABC and HLA-DR expression than BM-MSCs. In addition, UCMSCs with a wide variety of stem cells are well-sourced, easy to collect and preserve. UC-MSCs are expected to be an ideal alternative source for BM-MSCs. UC-MSCs play a unique role in reducing incidence and severity of graft versus host disease (GVHD) which occurs in more than $50 \%$ of patients undergoing hematopoietic stem cell transplantation (HSCT) (Zhao et al., 2019). 
Besides, based on their migratory capability toward cancer cells, many reports have proposed UC-MSCs as cell therapy to target tumors and to locally deliver anti-cancer molecules (Bajetto et al., 2017). However, various aspects of research on UC-MSCs are still in their infancy. The present review briefly overviews biological characteristics of UC-MSCs, current research advances and their application in treatment of hematological diseases.

\section{BIOLOGICAL CHARACTERISTICS OF UC-MSCs}

\section{Immunological Properties of UC-MSCs}

UC-MSCs are mainly located in subcortical endothelium of umbilical cord, perivascular region and Wharton's Jelly (WJ), which was mainly composed of sponge-like structure woven with collagen fibers, proteoglycans and embedded stromal cells (Watson et al., 2015). Flow cytometry analysis of UC-MSCs from WJ showed that CD24 and CD108 were highly expressed, while the expression of fibroblast-specific markers (FAP and FSP) and dermal fibroblast marker CD40 were very low. This suggests that WJ is a region rich in MSCs (Subramanian et al., 2015). UC-MSCs could express characteristic markers of various cells. In addition to expressing MSCs markers (CD105, CD90, CD73), UC-MSCs also expressed adhesion molecule markers (CD54, CD13, CD29, CD44). Low or no expression of CD31, CD14, CD34, CD45 and other hematopoietic stem cell-associated surface antigens; no expression immune responserelated antigens involved in $\mathrm{T}$ lymphocyte activation, such as CD80, CD86 and CD40, CD40L and major histocompatibility complex (MHC) class II antigen HLA-DR (Wang et al., 2014; Stefanska et al., 2020). The expression of CD106 and HLA$\mathrm{ABC}$ in UC-MSCs were significantly lower than that of BMderived cells, which result in low immunogenicity of UC-MSCs (Lu et al., 2006).

\section{Proliferation and Differentiation Potential of UC-MSCs}

WJ-MSCs displayed the highest proliferation rate with three to four times higher than that of adipose tissue (AT-) and BMMSCs (Amable et al., 2014; Kim et al., 2018). The Mennan team's report indicated that there was no significant difference in proliferation rate no matter what compartment UC-MSCs come from, and the average doubling time of UC-MSCs between P0 and P3 was 2-3 days, significantly faster than BM-MSCs (Mennan et al., 2013). UC-MSCs have the ability of multidirectional differentiation and have potential to differentiate into bone, adipose, cartilage and other tissues (Kfoury and Scadden, 2015; Richardson et al., 2016; Liu et al., 2018; Zhang et al., 2018; Shen et al., 2019; Yea et al., 2020), thus they can be used to repair various tissues and organs, and are ideal seed cells in the field of regenerative medicine (Wang et al., 2020). Studies have shown that when body tissues suffer from ischemia-anoxia injury or chronic inflammation, the damaged tissue released chemokines, mobilized and guided the migration of MSCs to the injury site, and further induced differentiation into different types of cells
(Kidd et al., 2010). In vitro culture, UC-MSCs can be "transdifferentiated" under certain conditions to become mesoderm cells such as osteoblasts (Xue et al., 2018) and cardiomyocytes (Wu et al., 2018), endothelial cells (Motawea et al., 2020), and also can differentiate into neurons in the ectoderm, hepatocytes (Zhou et al., 2017), pancreatic cells (Van Pham et al., 2014) in endoderm between germ layer. The low immunogenicity, high proliferation and differentiation potential of UC-MSCs make them seed cells for cell replacement therapy.

\section{THE MECHANISM OF UC-MSCs APPLIED TO HEMATOLOGIC DISEASES}

\section{UC-MSCs Support Hematopoiesis and Promote Engraftment and Expansion of HSCs}

UC-MSCs have been shown to support HSCs growth in vitro and in vivo (Fan and Zhang, 2011; Fajardo-Orduna et al., 2017). MSCs play an important role in regulating hematopoiesis and supporting engraftment and expansion of HSCs by secreting various adhesion molecules, cytokines and cell-cell contact interactions (Friedman et al., 2007; Le Blanc et al., 2007). When UC-MSC and HSCs were co-cultured in vitro, MSC highly expressed hematopoietic related factors promoting the growth of HSCs, and no significant difference was observed in colony-forming cells between the CD34 + cells/UC-MSC and CD34 + cells/BM-MSC co-cultures, which indicated that as a source of MSCs for cell therapies, UC was an excellent alternative to BM (Lu et al., 2006). Cytokine spectroscopy studies showed that UC-MSCs, like BM-MSC, expressed stem cell factor (SCF), leukemia inhibitory factor (LIF), macrophage-colony stimulating factor (M-CSF), FMS-like tyrosine kinase 3 (FLT3), interleukin6 (IL-6) and stromal cell derived factor-1 (SDF-1) (Lu et al., 2006). Moreover, UC-MSC also produced cytokine such as granulocyte colony-stimulation factor (G-CSF) and granulocytemacrophage colony stimulating factor (GM-CSF), which were not found in BM-MSC (Lu et al., 2006; Friedman et al., 2007). These cytokines are associated with HSCs proliferation, survival and differentiation. In a study by Bakhshi et al. (2010), UCMSCs supported the growth of $\mathrm{CD}_{3}{ }^{+}$cord blood cells in a long-term culture-initiating cell assay. UC-MSCs also increased homing and improved migration efficiency of UCB CD34 ${ }^{+}$ cells to bone marrow and spleen by expressing a high level of homing adhesion molecules (Hao et al., 2009). This suggested the potential therapeutic application of UC-MSCs to provide stromal support structure for the long-term culture of HSCs as well as the possibility of co-transplantation of genetically identical, HLAmatched, or unmatched cord blood HSCs (Bakhshi et al., 2010; Lin et al., 2020). There are some reports that the expression level of SDF-1 in UC-MSC is lower than that of MSC derived from bone marrow or adult tissue (Fonseka et al., 2013). SDF1 could inhibit apoptosis of stem cells and was associated with hematopoietic stem cell proliferation and survival, which indicated that UC-MSCs have weak hematopoietic supportive capacity than BM-MSCs. Overexpression of SCF and SDF-1 
by UC-MSCs in coculture system has efficient effect on the expansion of UCB-HSCs (Ajami et al., 2019).

\section{UC-MSCs Inhibit Proliferation of Hematological Malignancies Cell}

UC-MSCs participate in immune responses to tumor cells through various pathways. UC-MSCs do not induce tumorigenesis (Gauthaman et al., 2012)and also has anticancer properties (Wang et al., 2018; Li et al., 2019). The anti-cancer properties of UC-MSCs may be related to their low immunogenicity, the ability to secrete cytokines and transdifferentiate. Tian et al. (2010) believed that UC-MSCs could activate p38MAPK signaling pathway in HL-60 and K562 leukemia tumor cells, which has a strong inhibitory effect on the proliferation of these leukemia cells. This inhibition is achieved by arresting the cell cycle rather than by inducing apoptosis, indicating that UC-MSCs have the ability to induce tumor dormancy. There are other studies supporting the conclusion that UC-MSCs arrested tumor cells in specific phases of cell cycle, increased apoptosis and attenuated the migratory abilities of tumor cells (Yuan et al., 2018). In addition, Ramasamy et al. (2007) found that human bone marrow and cord blood-derived MSCs can down-regulate the expression of cyclin D2 and CDK4 with the inhibition of p27kip1 to arrest leukemia cells in Go or G1 phase to inhibit the proliferation of leukemia cells. In the subsequent study, they detected cytokines in co-culture supernatant of UC-MSCs and leukemia cell lines, and found that the expression of transforming growth factor- $\beta 1$ (TGF- $\beta 1$ ), IL- 6 , and IL-8 was significantly increased, to conclude that cytokines secreted by MSCs are related to their inhibition of leukemic cell proliferation (Fonseka et al., 2013). Besides, UC-MSCs or their secretions may induce lymphoma cell apoptosis by oxidative stress pathway (Lin et al., 2016). It was demonstrated that UC-MSCs induce T lymphocyte apoptosis and cell cycle arrest by expressing abundant IDO (Li et al., 2016). UC-MSC also inhibits proliferation of malignant cells as a member of immune cells. UC-MSCs may phagocytose some components of apoptotic lymphoma cells, so it could be speculated that UC-MSCs have the function of antigen presenting cells (Lin et al., 2014). In addition, UC-MSCs also exert anti-tumor effect as a carriers for gene or drug therapy (Zhang X. et al., 2017; Cao et al., 2018; Yuan L. et al., 2019). However, it is worth noting that some studies have shown that MSCs has the possibility to promote tumor progression (Li et al., 2018; Zhou et al., 2019). For example, PGE2 secreted by MSCs, can inhibit activity of $\mathrm{p} 53$, thereby promoting leukemogenesis and protecting against therapy-induced leukemic cell death through activation of cAMP-PKA signaling in BCP-ALL blasts (Naderi et al., 2015). The possible signaling pathways of UC-MSCs to malignant hematological cells is shown in Figure 1.

\section{UC-MSCs Inhibit Immune System}

The immunosuppressive function of MSCs is powerful and has varying degrees of effects on almost the entire immune network (Figure 2). Two different mechanisms, either cell contactdependent or -independent, have been advanced to explain this immunosuppression (Yang et al., 2017; Zhang H. et al., 2017; Min et al., 2020). The main way is to inhibit the proliferation of activated $\mathrm{T}$ lymphocytes and secretion of inflammatory factors, inhibit the proliferation of B lymphocytes and secretion of immunoglobulins, inhibit the killing activity of NK cells, and inhibit the differentiation of monocytes into dendritic cells (DCs) (Dabrowski et al., 2017; Xie et al., 2020).

UC-MSCs can release secretory soluble media such as IL-6, IL-8, TGF- $\beta$, IDO, vascular endothelial growth factor (VEGF) and cyclooxygenase-2 (COX-2), and prostaglandin E2 (PGE2), hepatocyte growth factor (HGF), Galectin-1 and HLA-G5 as an effective factor for immunosuppression (Amable et al., 2014; Ding et al., 2016; Abolhasani et al., 2018; Zhang et al., 2019). The secretion of inhibitory cytokines such as IL-10, IL-6, IL-8, TGF- $\beta 2$, and HGF inhibit Th17 cells and stimulate Treg cells, furthermore, UC-MSCs can also inhibit the proliferation of activated $\mathrm{T}$ cells by secreting IDO and PGE2, as well as upregulating the expression of programmed death ligand 1 (PD-L1) (Deng et al., 2016; Wang D. et al., 2017; Kim et al., 2018; Song et al., 2020). When the supernatants and cells produced by co-culture of UC-MSCs and phytohemagglutinin (PHA)-stimulated peripheral blood mononuclear cells (PBMCs) were compared with those of PHA-stimulated PBMCs without UC-MSCs, IFN- $\gamma$ was significant down-regulation while PGE2, TGF- $\beta 1$, and IL-10 were greatly up-regulated, meanwhile $\mathrm{CD} 4^{(+)} \mathrm{CD} 25$ (high)CD45RA ${ }^{(+)}$Tregs increased. This suggests that UC-MSCs can inhibit PHA- stimulated lymphocyte proliferation to exert immunosuppressive functions by regulating $\mathrm{T}$ cell differentiation and increasing the production of associated suppressive cytokines (Yang et al., 2016).

Upregulation of COX-2 expression by UC-MSCs also contributes to the production of PGE2, which directly inhibits $\mathrm{T}$ cell proliferation by increasing intracellular cAMP levels (van der Pouw Kraan et al., 1995; Kim et al., 2018). MSCs also inhibit $\mathrm{T}$ cell proliferation by eliminating tryptophan from the environment, and inhibit IFN- $\gamma$-activated $\mathrm{T}$ cells by IDO, which not only affects $\mathrm{T}$ cell proliferation but also reduces endogenous IFN- $\gamma$ production by $\mathrm{CD} 8+\mathrm{T}$ cells (Hong et al., 2016; Li et al., 2016). UC-MSCs also express nonclassical HLA class I molecule HLA-G (Ding et al., 2015). HLA-G regulates multiple $T$ cell subtypes: it not only inhibits $\mathrm{T}$ cell proliferation, but also attenuates cytotoxicity and cellmediated cytolysis (Ding et al., 2016; Szaraz et al., 2016). In addition, HLA-G molecules can induce $\mathrm{CD} 4^{+} \mathrm{CD} 25$ high $\mathrm{FOXP}^{+}$regulatory $\mathrm{T}$ cells, and inhibit the cytolytic function of NK cells to adjacent cells and down-regulate the secretion of IFN- $\gamma$ by NK cells (Selmani et al., 2010). UC-MSCs also induce DCs to acquire tolerogenic phenotype through IL-6mediated upregulation of suppressor of cytokine signaling 1 (SOCS1), which blocked DC maturation by impairing the TLR4 signaling leading to the immune tolerance. MSC-DCs showed a tolerogenic characteristics, the expression of co-stimulatory factors and the capacity to induce $\mathrm{CD} 3+\mathrm{T}$ cell proliferation and inflammatory factor secretion were significantly decreased, and the production of inhibitory cytokine IL-10 and the ability to induce Treg cells and Th2 responses increased (Deng et al., 2014; Yuan X. et al., 2019). 


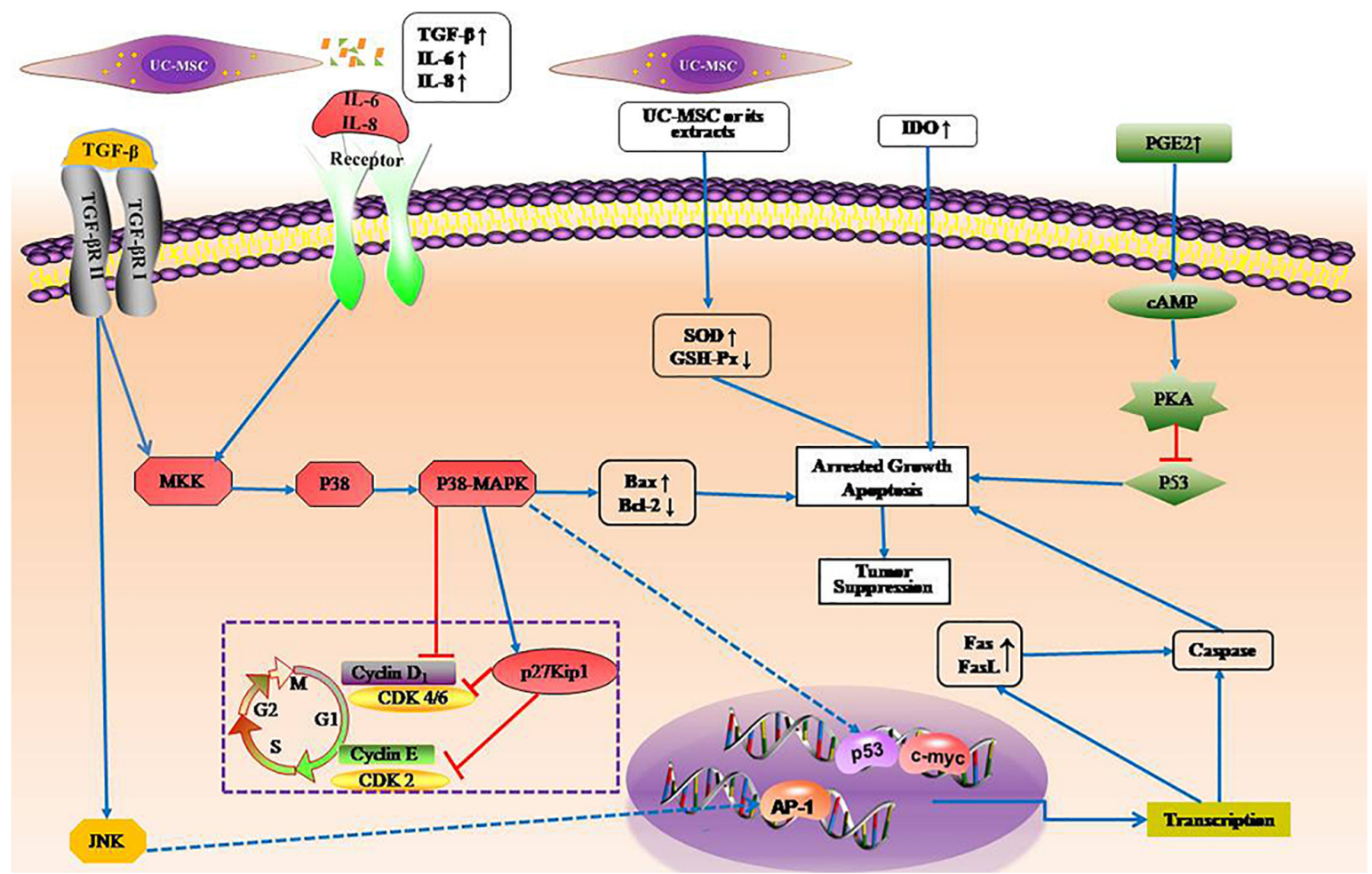

FIGURE 1 | Possible signal pathways of umbilical cord mesenchymal stem cells to hematological tumors. TGF $\beta$, IL6, and IL8 not only arrest cell cycle in Go or G1 phase inhibiting the proliferation of leukemia cells, but also promote apoptosis of leukemia cells. UC-MSCs or their secretions induce lymphoma cell apoptosis by oxidative stress pathway by enhancing SOD activity and decreasing GSH-Px activity. Forced expression of IDO enhance proliferation inhibitory effect on leukemia cells. PGE2 promoting leukemogenesis by inhibiting activity of p53 via cAMP-PKA pathway. SOD, superoxide dismutase; GSH-Px, glutathione peroxidase; IDO, indoleamine 2,3-dioxygenase.

\section{APPLICATION OF UC-MSCs IN HEMATOLOGIC DISEASES}

\section{Rationality of UC-MSCs Combined Hematopoietic Stem Cell Transplantation}

Hematological diseases are a series of heterogeneous diseases associated with abnormal blood changes that originate from the hematopoietic system or affect the hematopoietic system. Autologous or allogeneic HSCT are critical therapy tools to treat malignant and non-malignant hematological diseases (Bair et al., 2020; Mallhi et al., 2020). In order to completely clear immune system of recipient before HSCT, it is necessary to use high-dose chemotherapy drugs for pretreatment. However, the negative effects of bone marrow hematopoietic microenvironment damage and delayed immune reconstitution may lead to poor stem cell engraftment, and increase the rate of postoperative infection and recurrence (Bair et al., 2020; Mallhi et al., 2020). A series of animal and clinical trials showed that HSCT or cord blood transplantation (CBT) combined with infusion of UC-MSCs is able to promote hematopoietic engraftment and reduce the occurrence GVHD (Liu et al., 2020c; Yang et al., 2020). It was reported that UC-MSCs promote myeloid-derived suppressor cell proliferation by secreting HLA-G to reduce acute GVHD after HSCT (Yang et al., 2020). UC-MSCs produce an immunosuppressive isoform of HLA-1, do not express HLA-DR and lack costimulatory signaling systems and immune responserelated surface antigens such as CD40, CD40L, CD80, and CD86, which indicate that UC-MSCs can be tolerated in allogeneic transplantation (Wang et al., 2014). There were no reports of any toxicity or side effects when UC-MSCs were injected into laboratory animals in pre-clinical trials (Fan and Zhang, 2011), or were used to treat aplastic anemia (Xu et al., 2018; Liu et al., 2020c), leukemia (Kang-Hsi et al., 2013; Wu Y. et al., 2013) in clinical studies. This indicates that it is safe enough to use allogeneic MSCs after the HLA molecule is detected.

\section{The Ability of UC-MSCs to Treat Graft Versus Host Response}

GVHD is an immunological disorder that donor immune cells attack healthy recipient tissues, including gastrointestinal tract, liver, skin, and lungs, posing a threat to life (Nassereddine et al., 2017). Gao et al. (2016) have reported that repeated infusion of MSCs after patients' allogeneic hematopoietic stem cell transplantation (Allo-HSCT) can increase Treg cell, decrease memory B lymphocytes and NK cells, and change the ratio of Th1:Th2 cells, leading to the acquisition of immune tolerance, and then inhibit GVHD, improve transplantation survival rate. No serious side effects were found after infusion of 3/6-5/6 


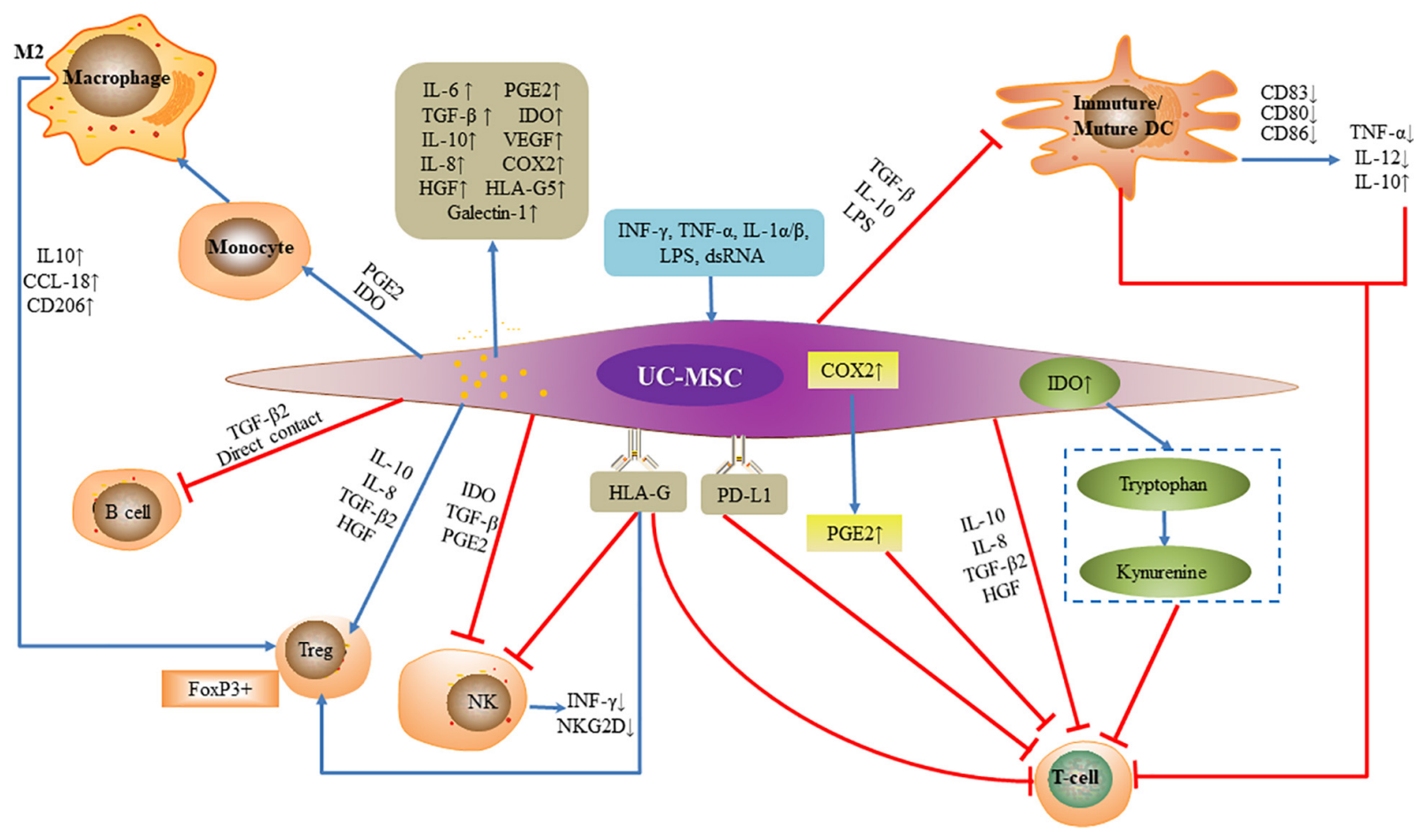

FIGURE 2 | Immunomodulatory function of umbilical cord mesenchymal stem cells. Under the license of INF- $\gamma$, TNF- $\alpha$, IL- $1 \alpha / \beta$, LPS, and dsRNA, umbilical cord mesenchymal stem cells secrete inflammatory factors and alter the expression of surface antigen to exert effects. Umbilical cord mesenchymal stem cells inhibit the proliferation and cytotoxicity of activated T lymphocytes, and secretion of inflammatory factors, inhibit B lymphocytes and secretion of immunoglobulins, inhibit NK cell killing activity and proliferation, and inhibit differentiation of monocytes into DCs achieving tolerogenic phenotype. Umbilical cord mesenchymal stem cells promote regulatory $T$ cells.

HLA-matched UC-MSCs, and the engraftment of neutrophils and platelets was faster in patients who co-transplanted with cord blood and UC-MSCs than in patients who received CBT alone. This suggests that UC-MSCs enhance engraftment after CBT (Wu K.H. et al., 2013). Peng et al. (2015) treated chronic GVHD with MSCs in 23 patients, and 20 patients were found to have complete or partial remission after 1 year of follow-up. In these patients who achieved MSCs treatment, the number of IL-10-producing CD5 + regulatory B cells (Bregs) significantly increased, and CD5 + B cells showed increased IL-10 expression, which was associated with reduced inflammatory cytokine production by $\mathrm{T}$ cells. The mechanism was that MSCs could promote the survival and proliferation of CD5 + Bregs, and IDO partially participates in the MSC-mediated effects on Bregs. It was also reported by other study that UC-MSCs boosted the numbers of $\mathrm{CD} 5^{(+)} \mathrm{B}$ cells and IL-10-producing $\mathrm{CD} 5^{(+)}$Bregs, and corrected Treg/Th17/Th1 imbalances (Chao et al., 2016). Yang et al. (2020) believed that UC-MSCs promote myeloid-derived suppressor cell proliferation by secreting HLA-G to reduce acute GVHD after HSCT. In a mouse model of allo-HSCT, after intravenously administered exosomes of UC-MSCs to recipient mice, the frequencies and absolute numbers of $\mathrm{CD}^{+} \mathrm{CD}^{+} \mathrm{T}$ cells decreased, the proportion of $\mathrm{CD}^{+}{ }^{+} \mathrm{CD} 4^{+}$and $\mathrm{CD} 3{ }^{+} \mathrm{CD} 8^{+}$ T cells increased, meanwhile, the serum levels of IL-2, TNF- $\alpha$, and IFN- $\gamma$ reduced, but IL-10 increased. In this way, the occurrence of acute GVHD is prevented (Wang et al., 2016). These findings suggest that UC-MSCs are ideal alternative in the prophylaxis of GVHD after allo-HSCT (Table 1). University of Kansas Medical Center is conducting clinical trial about the evaluation of UCMSCs for the treatment of acute GVHD (NCT03158896).

\section{The Ability of UC-MSCs to Treat Aplastic Anemia}

Severe aplastic anemia (SAA) is a life-threatening condition characterized by bone marrow hypoplasia and pancytopenia (Bacigalupo, 2017). Allo-HSCT is recommended as the firstline treatment in young patients with an available matched related donor (MRD) and as the second-line treatment in older patients who failed immunosuppressive therapy (IST) (Killick et al., 2016; Bacigalupo, 2017). IST with a combination of antithymocyte globulin (ATG) and cyclosporin A (CsA) is the preferred first-line treatment for patients without an MRD and older patients (Young, 2018). However, about 30-40\% of the patients will eventually relapse or become refractory to IST; those unresponsive to initial IST will be considered for transplantation using an alternative donor (Liu et al., 2020a). However, transplantation in patients with acquired SAA often fail to recover, and graft failure and rejection remain a common fatal risk for patients. When co-transplantation of haplo-HSCT and the donor-derived UC-MSCs for SAA patients, it had fewer complications, accelerated hematopoietic reconstitution, reduced 
TABLE 1 | Application of UC-MSCs in hematologic diseases.

\begin{tabular}{|c|c|c|}
\hline $\begin{array}{l}\text { Type of } \\
\text { disease }\end{array}$ & The Role of UC-MSCs & $\begin{array}{l}\text { Possible mechanisms of } \\
\text { therapeutic effect by MSCs }\end{array}$ \\
\hline $\begin{array}{l}\text { Malignant } \\
\text { hematological } \\
\text { diseases: } \\
\text { non-Hodgkin's } \\
\text { lymphoma }\end{array}$ & $\begin{array}{l}\text { As cell carriers (such as } \\
\text { MSC-Tandab } \\
\text { (CD3/CD19) and } \\
\text { scFvCD20-sTRAIL) to } \\
\text { treat hematological } \\
\text { malignancies }\end{array}$ & $\begin{array}{l}\text { - Tumor tropism } \\
\text { - Low immunogenicity } \\
\text { - Easy expansion }\end{array}$ \\
\hline $\begin{array}{l}\text { Malignant and } \\
\text { non-malignant } \\
\text { hematological } \\
\text { diseases }\end{array}$ & $\begin{array}{l}\text { Co-transplantation with } \\
\text { HSCT to reduce GVHD } \\
\text { and promote } \\
\text { hematopoietic } \\
\text { engraftment }\end{array}$ & 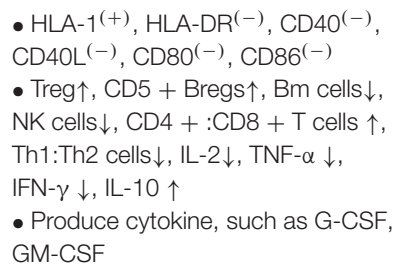 \\
\hline SAA & $\begin{array}{l}\text { Improve survival and } \\
\text { quality of life in patients } \\
\text { with SAA by } \\
\text { co-transplantation with } \\
\text { HSCT or PBSCs }\end{array}$ & $\begin{array}{l}\text { - Accelerated hematopoietic } \\
\text { reconstitution } \\
\text { - Reduced incidence of severe } \\
\text { GVHD and transplant-related } \\
\text { mortality }\end{array}$ \\
\hline APL & $\begin{array}{l}\text { The potential to treat } \\
\text { APL }\end{array}$ & $\begin{array}{l}\text { - Activating MEK/ERK signaling to } \\
\text { induce granulocyte differentiation of } \\
\text { APL-derived NB4 cell lines and } \\
\text { primary APL cells }\end{array}$ \\
\hline ITP & The potential to treat ITP & $\begin{array}{l}\text { - Regulate secretion of PAlgG } \\
\text { - Inhibited the proliferation of } \\
\text { platelet-reactive T helper cell } \\
\text { - Promoting platelet production } \\
\text { - Reversed the dysfunctions of } \\
\text { megakaryocytes }\end{array}$ \\
\hline
\end{tabular}

APL, acute promyelocytic leukemia; Bm cells, memory B cells; G-CSF, granulocyte colony-stimulation factor; GM-CSF, granulocyte-macrophage colony stimulating factor; GVHD, graft versus host disease; HLA, human leukocyte antigen; HSCT, hematopoietic stem cell transplantation; ITP, Immune thrombocytopenic; MSC, mesenchymal stem cells; PAlgG, IgG antiplatelet antibody; SAA, severe aplastic anemia; SCFVCD20-sTRAIL, contains a CD20-specific single chain FV antibody fragment ( $S C F V)$ and a soluble tumor necrosis factor related apoptosis-inducing ligand (sTRAIL); Tandab (CD3/CD19), tetravalent bispecific tandem diabody with two binding sites for CD3 and two for CD19.

incidence of severe GVHD and transplant-related mortality (Wu et al., 2014; Liu et al., 2020b). In addition, several studies have shown that co-transplantation of haplo-HSCT and UC-MSCs from third-party donors has yielded favorable results for SAA patients: overall survival and GVHD-free are improved, which demonstrate a feasible choice for SAA patients without matched donors in improving donor engraftment and reducing severe GVHD (Wu et al., 2011; Liu et al., 2020b). Clinical data from co-transplantation of unrelated donor peripheral blood stem cell (PBSCs) and UC-MSCs for young patients with refractory SAA also showed similar results (Fu et al., 2013). Consequently, cotransplantation with UC-MSCs can greatly improve survival and quality of life in patients with SAA (Table 1).

\section{The Ability of UC-MSCs to Treat Hematological Malignancies}

Co-transplantation of haplo-HSCT with third-party donorderived UC-MSCs can also be used in refractory/recurrent hematologic malignancies to improve donor engraftment and reduce GVHD (Wu Y. et al., 2013; Zhao et al., 2019). MSCs may be a double-edged sword. Studies have shown that patients with hematologic malignancies undergoing co-transplantation of BM-MSC and HSC after chemotherapy have a higher tumor recurrence rate than patients who only received HSC transplantation (Ning et al., 2008). Other study demonstrated that use of UC-MSCs tended to reduce relapse, whereas use of BM-MSCs tended to increase relapse (Zhao et al., 2019). Those findings suggested that BM-MSCs were not a good candidate cell type for GVHD prophylaxis in comparison with UC-MSCs. But it was also worth noting that UC-MSCs was proved to promote the proliferation of Raji cells in vitro ( $\mathrm{Li}$ et al., 2018). MSC co-transplantation in allo-HSCT should be applied in the non-malignant hematopoietic diseases other than malignant hematopoietic diseases at present (Ning et al., 2008). We therefore need to seriously study the relationship between MSCs infusion and disease recurrence, and take corresponding measures to improve the safety and effectiveness of MSCs for the treatment of hematological malignancies. The use of MSCs must be handled with extreme caution before a large-scale clinical trial is performed.

Acute promyelocytic leukemia (APL) is characterized by accumulation of cells blocked in promyelocytic phase. The treatment outcome of APL has dramatically improved over the past three decades following the development of novel agents, such as all-trans retinoic acid (ATRA), which induce terminal differentiation of APL cells into mature granulocytes (Sanz et al., 2019). It has been reported that UC-MSCs can exert similar effects, possibly by activating the MEK/ERK signaling to induce granulocyte differentiation of APL-derived NB4 cell lines as well as primary APL cells. These results demonstrate a stimulatory effect of MSCs on the differentiation of APL cells and bring a new insight into the interaction between MSCs and leukemic cells. It suggest that UC-MSCs/ATRA combination could be used as a novel therapeutic strategy for APL patients (Chen et al., 2013; Table 1).

\section{UC-MSCs as Cell Carriers to Treat Hematological Malignancies}

Multiple chemotherapeutic and molecular targeted agents are available for the treatment of hematological malignancies (Deshantri et al., 2018; Testa et al., 2019). However, only a subset of patients will achieve long-term remission or complete cure of the disease, which is at least partly due to the lack of specificity of these agents for the disease site and their short biological half-lives. Lack of specificity results in off-target adverse effects, and high doses and frequent dosing to maintain the therapeutic levels further increase adverse effects (Egusquiaguirre et al., 2012; Deshantri et al., 2018). Drug delivery systems could be essential to retain the active substance in the circulation and deliver it to the malignant cells (Galderisi et al., 2010; Deshantri et al., 2018). UC-MSCs are an attractive candidate as cell carriers for cell-based therapy to treat malignant diseases because they have ability to migrate to tumor sites and track micrometastasis (Galderisi et al., 2010; Bajetto et al., 2017). The tumor tropism, low immunogenicity and easy expansion with a consistent collection 
process make MSCs an ideal delivery vehicle for anti-tumor factors (Galderisi et al., 2010). Accurate treatment for anti-tumor can be achieved owing to the delivery vehicles allowing specific tumor targeting and controlled release strategies (Table 1; Jing et al., 2014; Shou et al., 2016).

Bispecific $\mathrm{T}$ cell engaging antibody, exhibits high clinical response rates in patients with relapsed or refractory B-precursor acute lymphoblastic leukemia (B-ALL) and B cell non-Hodgkin's lymphoma (B-NHL), but it still has some limitations because of its short half-life. When human UC-MSCs were genetically modified to constitutively secrete Tandab (CD3/CD19) (MSCTandab), a tetravalent bispecific tandem diabody with two binding sites for CD3 and two for CD19, MSC-Tandab was functional with high-binding capability both for CD3-positive cells and CD19-positive cells and can induce specific lysis of CD19-positive cell lines in the presence of $\mathrm{T}$ cells. Luciferaselabeled MSCs could selectively migrate to tumor site in BALB/c nude mouse model to significantly inhibit the tumor growth (Zhang X. et al., 2017). Xiong et al. designed a promising doubletarget therapeutic system for NHL therapy. In this system, a novel secreted fusion protein scFvCD20-sTRAIL, which contains a CD20-specific single chain Fv antibody fragment (scFv) and a soluble tumor necrosis factor related apoptosis-inducing ligand (sTRAIL), was expressed in UC-MSCs. The scFvCD20-sTRAIL fusion protein could inhibit cell proliferation and increase cellular apoptosis through both extrinsic and intrinsic apoptosis signaling pathways. UC-MSCs selectively migrated to the tumor site after $24 \mathrm{~h}$ of intravenous injection and tumor growth was significantly inhibited with well tolerated and no toxic reactions occurred (Yan et al., 2013).

\section{The Ability of UC-MSCs to Treat Immune Thrombocytopenic Purpura}

Immune thrombocytopenic (ITP) is an autoimmune disease characterized by antibody-mediated platelet destruction and variable reduced platelet production (Tinazzi et al., 2020). Other immune dysfunctions also participate in ITP pathogenesis, including numeric and functional defects in suppressor $\mathrm{T}$ (Ts) cells and immune-regulation abnormalities in MSCs (Li et al., 2020). Firstline treatments include steroids and intravenous immunoglobulins, and thrombopoietin receptor agonists (TPORAs) and rituximab were also frequently used before the chronic phase (Moulis et al., 2017; Mahevas et al., 2020). Recent studies conclude that defects of BM-MSCs in Ts cell induction are involved in ITP pathogenesis, and exogenous UC-MSCs may be useful for ITP therapy (Li et al., 2020). When UC-MSCs were co-cultured with splenocytes isolated from patients with ITP in vitro, the results showed that UCMSCs could stimulate the spontaneous secretion of anti-platelet antibody IgG (IgG antiplatelet antibody, PAIgG). However, under platelet-inducing conditions, UC-MSCs inhibited the production of PAIgG at a low ratio of UC-MSC to splenocytes. In addition, UC-MSC inhibited the proliferation of plateletreactive $\mathrm{T}$ helper cell in a dose-dependent manner. Therefore, UC-MSCs can regulate secretion of antiplatelet antibodies in vitro (Qiu et al., 2008). Not just in vitro, UC-MSCs has been used to treat ITP in vivo (Ma et al., 2012; Wang X. et al., 2017). UC-MSCs obviously reversed the dysfunctions of megakaryocytes by promoting platelet production and decreasing the number of living megakaryocytes as well as early apoptosis. The level of thrombopoietin and platelet numbers was also significantly increased to alleviate refractory ITP. These findings suggested that UC-MSCs transplantation might be a potential therapy for ITP (Table 1). The clinical trial of UC-MSCs for treatment of refractory ITP is recruiting (NCT04014166). However, the clinical application of UCMSCs in treatment of ITP is not yet mature, and its specific regulatory mechanisms and potential immunotherapeutic value need further study.

\section{CONCLUSION}

The low immunogenicity and immunoregulatory activity of UC-MSCs made it particularly attractive for therapeutic exploitation, which provided the footstone of inhibiting the growth of tumor cells, improving the complications after hematopoietic stem cell transplantation, promoting hematopoiesis for hematologic diseases. Although the research on UC-MSCs has achieved encouraging results, there are still some problems to be solved: The MSCs isolated by the current method have no specific phenotype, leading to a group of mixed cells with different characteristics. It is necessary to explore appropriate cell surface molecular markers for separation and purification, find means to control their growth and differentiation, and investigate whether there is a sign of malignant tendency and malignant transformation after long-term cultivation (Jeschke, 2011). Besides, the MSCs alone have no immunosuppressive effect, but have to be licensed by cytokines such as TNF- $\alpha$ and IFN- $\gamma$, and UC-MSCs do not spontaneously form medullary cavities like BM-MSCs through vascularized cartilage intermediates in vivo (English, 2013). It will be the main research direction to improve the isolation and culture of MSCs, clarify the mechanisms in immunosuppression and further explore differentiation potential of UC-MSCs. It is believed that with the deepening of research, the application prospect of UC-MSCs in hematologic diseases will become much broader.

\section{AUTHOR CONTRIBUTIONS}

FZ contributed to the conception, logic and revision of the review. YS and HG contributed to the writing and drafting of the manuscript. All authors contributed to the article and approved the submitted version.

\section{FUNDING}

This work was supported by the National Natural Science Foundation of China under Grant (Grant No. 81770179). 


\section{REFERENCES}

Abolhasani, M., Rezaee, M. A., Mohammadi, M., Ghadimi, T., Mohammadi, M., and Rahmani, M. R. (2018). Immunomodulatory properties of umbilical cord vein mesenchymal stromal cells influenced by gestational age and in vitro expansion. Immunol. Lett. 194, 62-68. doi: 10.1016/j.imlet.2017.11.008

Ajami, M., Soleimani, M., Abroun, S., and Atashi, A. (2019). Comparison of cord blood CD34 + stem cell expansion in coculture with mesenchymal stem cells overexpressing SDF-1 and soluble /membrane isoforms of SCF. J. Cell Biochem. 120, 15297-15309. doi: 10.1002/jcb.28797

Amable, P. R., Teixeira, M. V. T., Carias, R. B. V., Granjeiro, J. M., and Borojevic, R. (2014). Protein synthesis and secretion in human mesenchymal cells derived from bone marrow, adipose tissue and Wharton's jelly. Stem Cell Res. Ther. 5:53. doi: $10.1186 /$ scrt442

Bacigalupo, A. (2017). How I treat acquired aplastic anemia. Blood 129, 1428-1436. doi: 10.1182/blood-2016-08-693481

Bair, S. M., Brandstadter, J. D., Ayers, E. C., and Stadtmauer, E. A. (2020). Hematopoietic stem cell transplantation for blood cancers in the era of precision medicine and immunotherapy. Cancer 126, 1837-1855. doi: 10.1002/ cncr.32659

Bajetto, A., Pattarozzi, A., Corsaro, A., Barbieri, F., Daga, A., Bosio, A., et al. (2017). Different effects of human umbilical cord Mesenchymal stem cells on glioblastoma stem cells by direct cell interaction or via released soluble factors. Front. Cell Neurosci. 11:312. doi: 10.3389/fncel.2017.00312

Bakhshi, T., Zabriskie, R. C., Bodie, S., Kidd, S., Ramin, S., Paganessi, L. A., et al. (2010). Mesenchymal stem cells from the Wharton's jelly of umbilical cord segments provide stromal support for the maintenance of cord blood hematopoietic stem cells during long-term ex vivo culture. Transfusion 48, 2638-2644. doi: 10.1111/j.1537-2995.2008.01926.x

Cao, S., Guo, J., He, Y., Alahdal, M., Tang, S., Zhao, Y., et al. (2018). Nanoloaded human umbilical cord mesenchymal stem cells as targeted carriers of doxorubicin for breast cancer therapy. Artif. Cells Nanomed. Biotechnol. 46, 642-652. doi: 10.1080/21691401.2018.1434185

Chao, K., Zhang, S., Qiu, Y., Chen, X., Zhang, X., Cai, C., et al. (2016). Human umbilical cord-derived mesenchymal stem cells protect against experimental colitis via CD5(+) B regulatory cells. Stem Cell Res. Ther. 7:109. doi: 10.1186/ s13287-016-0376-2

Chen, F., Zhou, K., Zhang, L., Ma, F., Chen, D., Cui, J., et al. (2013). Mesenchymal stem cells induce granulocytic differentiation of acute promyelocytic leukemic cells via IL-6 and MEK/ERK pathways. Stem Cells Dev. 22:1955. doi: 10.1089/ scd.2012.0621

Dabrowski, F. A., Burdzinska, A., Kulesza, A., Sladowska, A., Zolocinska, A., Gala, K., et al. (2017). Comparison of the paracrine activity of mesenchymal stem cells derived from human umbilical cord, amniotic membrane and adipose tissue. J. Obstet. Gynaecol. Res. 43, 1758-1768. doi: 10.1111/jog.13432

Deng, Y., Yi, S., Wang, G., Cheng, J., Zhang, Y., Chen, W., et al. (2014). Umbilical cord-derived mesenchymal stem cells instruct dendritic cells to acquire tolerogenic phenotypes through the IL-6-mediated upregulation of SOCS1. Stem Cells Dev. 23, 2080-2092. doi: 10.1089/scd.2013.0559

Deng, Y., Zhang, Y., Ye, L., Zhang, T., Cheng, J., Chen, G., et al. (2016). Umbilical cord-derived mesenchymal stem cells instruct monocytes towards an IL10producing phenotype by secreting IL6 and HGF. Sci. Rep. 6:37566. doi: 10.1038/ srep37566

Deshantri, A. K., Varela Moreira, A., Ecker, V., Mandhane, S. N., Schiffelers, R. M., Buchner, M., et al. (2018). Nanomedicines for the treatment of hematological malignancies. J. Control Release 287, 194-215. doi: 10.1016/j.jconrel.2018. 08.034

Ding, D. C., Chou, H. L., Chang, Y. H., Hung, W. T., Liu, H. W., and Chu, T. Y. (2015). Characterization of HLA-G and related immunosuppressive effects in human umbilical cord stroma derived stem cells. Cell Transpl. 19, 623-630.

Ding, D. C., Chou, H. L., Chang, Y. H., Hung, W. T., Liu, H. W., and Chu, T. Y. (2016). Characterization of HLA-G and related immunosuppressive effects in human umbilical cord stroma-derived stem cells. Cell Transpl. 25, 217-228. doi: 10.3727/096368915X688182

Egusquiaguirre, S. P., Igartua, M., Hernandez, R. M., and Pedraz, J. L. (2012). Nanoparticle delivery systems for cancer therapy: advances in clinical and preclinical research. Clin. Transl. Oncol. 14, 83-93. doi: 10.1007/s12094-0120766-6
English, K. (2013). Mechanisms of mesenchymal stromal cell immunomodulation. Immunol. Cell Biol. 91, 19-26. doi: 10.1038/icb.2012.56

Fajardo-Orduna, G. R., Mayani, H., Flores-Guzman, P., Flores-Figueroa, E., Hernandez-Estevez, E., Castro-Manrreza, M., et al. (2017). Human mesenchymal stem/stromal cells from umbilical cord blood and placenta exhibit similar capacities to promote expansion of hematopoietic progenitor cells in vitro. Stem Cells Int. 2017, 6061729. doi: 10.1155/2017/6061729

Fan, C. G., and Zhang, Q. J. (2011). Therapeutic potentials of mesenchymal stem cells derived from human umbilical cord. Stem Cell Rev. Rep. 7, 195-207. doi: 10.1007/s12015-010-9168-8

Fonseka, M., Ramasamy, R., Tan, B. C., and Seow, H. F. (2013). Human umbilical cord blood-derived mesenchymal stem cells (hUCB-MSC) inhibit the proliferation of K562 (human erythromyeloblastoid leukaemic cell line). Cell Biol. Intern. 36, 793-801. doi: 10.1042/cbi20110595

Friedman, R., Betancur, M., Boissel, L., Tuncer, H., Cetrulo, C., and Klingemann, H. (2007). Umbilical cord mesenchymal stem cells: adjuvants for human cell transplantation. Biol. Blood Marrow Transpl. 13, 1477-1486. doi: 10.1016/j. bbmt.2007.08.048

Fu, Y., Wang, Q., Zhou, J., Liu, S., Fang, B., Wei, X., et al. (2013). Reduced intensity conditioning and co-transplantation of unrelated peripheral stem cells combined with umbilical cord mesenchymal stem/stroma cells for young patients with refractory severe aplastic anemia. Intern. J. Hematol. 98, 658-663. doi: 10.1007/s12185-013-1425-6

Galderisi, U., Giordano, A., and Paggi, M. G. (2010). The bad and the good of mesenchymal stem cells in cancer: boosters of tumor growth and vehicles for targeted delivery of anticancer agents. World J. Stem Cells 2, 5-12. doi: 10.4252/ wjsc.v2.i1.5

Gao, L., Zhang, Y., Hu, B., Liu, J., Kong, P., Lou, S., et al. (2016). Phase II multicenter, randomized, double-blind controlled study of efficacy and safety of umbilical cord-derived mesenchymal stromal cells in the prophylaxis of chronic graft-versus-host disease after HLA-haploidentical stem-cell transplantation. J. Clin. Oncol. 34, 2843-2850. doi: 10.1200/jco.2015.65.3642

Gauthaman, K., Fong, C. Y., Suganya, C. A., Subramanian, A., Biswas, A., Choolani, M., et al. (2012). Extra-embryonic human Wharton's jelly stem cells do not induce tumorigenesis, unlike human embryonic stem cells. Reprod. Biomed. Online 24:235. doi: 10.1016/j.rbmo.2011.10.007

Hao, M., Meng, H. X., Li, G., Qi, P. J., Xu, Y., Li, C. H., et al. (2009). [Study of influence of umbilical cord mesenchymal stem cells on CD34+ cells in vivo homing in NOD/SCID]. Zhonghua Xue Ye Xue Za Zhi 30, 103-106.

Hong, J., Hueckelhoven, A., Wang, L., Schmitt, A., Wuchter, P., Tabarkiewicz, J., et al. (2016). Indoleamine 2,3-dioxygenase mediates inhibition of virus-specific CD8(+) T cell proliferation by human mesenchymal stromal cells. Cytotherapy 18, 621-629. doi: 10.1016/j.jcyt.2016.01.009

Jeschke, M. G. (2011). Umbilical cord lining membrane and Wharton's jellyderived mesenchymal stem cells: the similarities and differences. Open Tissue Eng. Regener. Med. J. 4, 21-27. doi: 10.2174/1875043501104010021

Jing, W., Chen, Y., Lu, L., Hu, X., Shao, C., Zhang, Y., et al. (2014). Human umbilical cord blood-derived mesenchymal stem cells producing IL15 eradicate established pancreatic tumor in syngeneic mice. Mol. Cancer Therapeut. 13:2127. doi: 10.1158/1535-7163.mct-14-0175

Kang-Hsi, W., Ji-Nan, S., Han-Ping, W., Chris, T., Martin, S., Ching-Tien, P., et al. (2013). Cotransplantation of umbilical cord-derived mesenchymal stem cells promote hematopoietic engraftment in cord blood transplantation: a pilot study. Transplantation 95:773. doi: 10.1097/tp.0b013e31827a93dd

Kern, S., Eichler, H., Stoeve, J., Klüter, H., and Bieback, K. (2006). Comparative analysis of mesenchymal stem cells from bone marrow, umbilical cord blood, or adipose tissue. Stem Cells 24, 1294-1301. doi: 10.1634/stemcells.2005-0342

Kfoury, Y., and Scadden, D. T. (2015). Mesenchymal cell contributions to the stem cell niche. Cell Stem Cell 16, 239-253. doi: 10.1016/j.stem.2015.02.019

Kidd, S., Spaeth, E., Dembinski, J. L., Dietrich, M., Watson, K., Klopp, A., et al. (2010). Direct evidence of mesenchymal stem cell tropism for tumor and wounding microenvironments using in vivo bioluminescent imaging. Stem Cells 27, 2614-2623. doi: 10.1002/stem.187

Killick, S. B., Bown, N., Cavenagh, J., Dokal, I., Foukaneli, T., Hill, A., et al. (2016). Guidelines for the diagnosis and management of adult aplastic anaemia. Br. J. Haematol. 172, 187-207. doi: 10.1111/bjh.13853

Kim, J. H., Jo, C. H., Kim, H. R., and Hwang, Y. I. (2018). Comparison of immunological characteristics of Mesenchymal stem cells from the periodontal 
ligament, umbilical cord, and adipose tissue. Stem Cells Int. 2018:8429042. doi: 10.1155/2018/8429042

Kobolak, J., Dinnyes, A., Memic, A., Khademhosseini, A., and Mobasheri, A. (2016). Mesenchymal stem cells: identification, phenotypic characterization, biological properties and potential for regenerative medicine through biomaterial micro-engineering of their niche. Methods 99, 62-68. doi: 10.1016/ j.ymeth.2015.09.016

Le Blanc, K., Samuelsson, H., Gustafsson, B., Remberger, M., Sundberg, B., Arvidson, J., et al. (2007). Transplantation of mesenchymal stem cells to enhance engraftment of hematopoietic stem cells. Leukemia 21, 1733-1738. doi: 10.1038/sj.leu.2404777

Li, H., Guan, Y., Sun, B., Dou, X., Liu, X., Xue, F., et al. (2020). Role of bone marrow-derived mesenchymal stem cell defects in CD8(+) CD28(-) suppressor T-lymphocyte induction in patients with immune thrombocytopenia and associated mechanisms. Br. J. Haematol. 191, 852-886. doi: 10.1111/bjh.16953

Li, Q., Pang, Y., Liu, T., Tang, Y., Xie, J., Zhang, B., et al. (2018). Effects of human umbilical cord-derived mesenchymal stem cells on hematologic malignancies. Oncol. Lett. 15, 6982-6990. doi: 10.3892/ol.2018.8254

Li, X., Liu, L. L., Yao, J. L., Wang, K., and Ai, H. (2019). Human umbilical cord mesenchymal stem cell-derived extracellular vesicles inhibit endometrial cancer cell proliferation and migration through delivery of exogenous miR-302a. Stem Cells Int. 2019:8108576. doi: 10.1155/2019/8108576

Li, X., Xu, Z., Bai, J., Yang, S., Zhao, S., Zhang, Y., et al. (2016). Umbilical Cord tissue-derived mesenchymal stem cells induce $\mathrm{T}$ lymphocyte apoptosis and cell cycle arrest by expression of indoleamine 2, 3-dioxygenase. Stem Cells Int. 2016:7495135. doi: 10.1155/2016/7495135

Lin, H. D., Fong, C. Y., Biswas, A., and Bongso, A. (2020). Allogeneic human umbilical cord Wharton's jelly stem cells increase several-fold the expansion of human cord blood CD34+ cells both in vitro and in vivo. Stem Cell Res. Ther. 11:527. doi: 10.1186/s13287-020-02048-0

Lin, H. D., Fong, C. Y., Biswas, A., Choolani, M., and Bongso, A. (2014). Human Wharton's jelly stem cells, its conditioned medium and cell-free Lysate inhibit the growth of human lymphoma cells. Stem Cell Rev. Rep. 10, 573-586. doi: 10.1007/s12015-014-9514-3

Lin, H. D., Fong, C. Y., Biswas, A., Choolani, M., and Bongso, A. (2016). Human umbilical cord Wharton's Jelly stem cell conditioned medium induces tumoricidal effects on lymphoma cells through hydrogen peroxide mediation. J. Cell Biochem. 117, 2045-2055. doi: 10.1002/jcb.25501

Liu, C., Zhang, H., Tang, X., Feng, R., Yao, G., Chen, W., et al. (2018). Mesenchymal stem cells promote the osteogenesis in collagen-induced arthritic mice through the inhibition of TNF-alpha. Stem Cells Int. 2018:4069032. doi: 10.1155/2018/ 4069032

Liu, L., Zhang, Y., Jiao, W., Zhou, H., Wang, Q., Jin, S., et al. (2020a). Comparison of efficacy and health-related quality of life of first-line haploidentical hematopoietic stem cell transplantation with unrelated cord blood infusion and first-line immunosuppressive therapy for acquired severe aplastic anemia. Leukemia 34, 3359-3369. doi: 10.1038/s41375-020-0933-7

Liu, L., Zhang, Y., Jiao, W., Zhou, H., Wang, Q., Qiu, H., et al. (2020b). Combination of haploidentical haematopoietic stem cell transplantation with an unrelated cord-blood unit in patients with severe aplastic anemia: a report of 146 cases. Bone Marrow Transpl. 55, 2017-2025. doi: 10.1038/s41409-0200874-9

Liu, Z., Wu, X., Wang, S., Xia, L., Xiao, H., Li, Y., et al. (2020c). Cotransplantation of mesenchymal stem cells makes haploidentical HSCT a potential comparable therapy with matched sibling donor HSCT for patients with severe aplastic anemia. Ther. Adv. Hematol. 11:2040620720965411. doi: $10.1177 / 2040620720965411$

Lu, L. L., Liu, Y. J., Yang, S. G., Zhao, Q. J., Wang, X., Gong, W., et al. (2006). Isolation and characterization of human umbilical cord mesenchymal stem cells with hematopoiesis-supportive function and other potentials. Haematologica 91, 1017-1026.

Ma, L., Zhou, Z., Zhang, D., Yang, S., Wang, J., Xue, F., et al. (2012). Immunosuppressive function of mesenchymal stem cells from human umbilical cord matrix in immune thrombocytopenia patients. Thromb. Haemost. 107, 937-950. doi: 10.1160/TH11-08-0596

Mahevas, M., Azzaoui, I., Crickx, E., Canoui-Poitrine, F., Gobert, D., Languille, L., et al. (2020). Efficacy, safety and immunological profile of combining rituximab with belimumab for adults with persistent or chronic immune thrombocytopenia: results from a prospective phase $2 \mathrm{~b}$ trial. Haematologica 2020:259481. doi: 10.3324/haematol.2020.259481

Mallhi, K. K., Srikanthan, M. A., Baker, K. K., Frangoul, H. A., Torgerson, T. R., Petrovic, A., et al. (2020). HLA-haploidentical hematopoietic cell transplantation for treatment of nonmalignant diseases using nonmyeloablative conditioning and post-transplant cyclophosphamide. Biol Blood Marrow Transpl. 26, 1332-1341. doi: 10.1016/j.bbmt.2020.03.018

Mennan, C., Wright, K., Bhattacharjee, A., Balain, B., Richardson, J., and Roberts, S. (2013). Isolation and characterisation of mesenchymal stem cells from different regions of the human umbilical cord. Biomed. Res. Intern. 2013:916136.

Min, H., Xu, L., Parrott, R., Overall, C. C., Lillich, M., Rabjohns, E. M., et al. (2020). Mesenchymal stromal cells reprogram monocytes and macrophages with processing bodies. Stem Cells 39, 115-128. doi: 10.1002/stem.3292

Motawea, S. M., Noreldin, R. I., and Naguib, Y. M. (2020). Potential therapeutic effects of endothelial cells trans-differentiated from Wharton's Jelly-derived mesenchymal stem cells on altered vascular functions in aged diabetic rat model. Diabetol. Metab. Syndr. 12:40. doi: 10.1186/s13098-020-00546-y

Moulis, G., Germain, J., Comont, T., Brun, N., Dingremont, C., Castel, B., et al. (2017). Newly diagnosed immune thrombocytopenia adults: clinical epidemiology, exposure to treatments, and evolution. Results of the CARMEN multicenter prospective cohort. Am. J. Hematol. 92, 493-500. doi: 10.1002/ajh. 24702

Naderi, E. H., Skah, S., Ugland, H., Myklebost, O., Sandnes, D. L., Torgersen, M. L., et al. (2015). Bone marrow stroma-derived PGE2 protects BCP-ALL cells from DNA damage-induced p53 accumulation and cell death. Mol. Cancer 14:14. doi: 10.1186/s12943-014-0278-9

Nassereddine, S., Rafei, H., Elbahesh, E., and Tabbara, I. (2017). Acute graft versus host disease: a comprehensive review. Anticancer Res. 37, 1547-1555. doi: 10. 21873/anticanres.11483

Ning, H., Yang, F., Jiang, M., Hu, L., Feng, K., Zhang, J., et al. (2008). The correlation between cotransplantation of mesenchymal stem cells and higher recurrence rate in hematologic malignancy patients: outcome of a pilot clinical study. Leukemia 22, 593-599. doi: 10.1038/sj.leu.2405090

Peng, Y., Chen, X., Liu, Q., Zhang, X., Huang, K., Liu, L., et al. (2015). Mesenchymal stromal cells infusions improve refractory chronic graft versus host disease through an increase of $\mathrm{CD} 5+$ regulatory B cells producing interleukin 10. Leukemia 29, 636. doi: 10.1038/leu.2014.225

Qiu, Z. Y., Yang, S. G., Chen, Z. P., Zhao, Q. J., Chen, X. L., Zhou, Z. P., et al. (2008). Mesenchymal stem cells derived from human umbilical cord tissue modulate the secretion of antiplatelet antibody from splenocytes of ITP patients in vitro. J. Exper. Hematol. 16, 1372-1375.

Ramasamy, R., Lam, E. W., Soeiro, I., Tisato, V., Bonnet, D., and Dazzi, F. (2007). Mesenchymal stem cells inhibit proliferation and apoptosis of tumor cells: impact on in vivo tumor growth. Leukemia 21, 304-310. doi: 10.1038/sj.leu. 2404489

Richardson, S. M., Kalamegam, G., Pushparaj, P. N., Matta, C., Memic, A., Khademhosseini, A., et al. (2016). Mesenchymal stem cells in regenerative medicine: focus on articular cartilage and intervertebral disc regeneration. Methods 99, 69-80. doi: 10.1016/j.ymeth.2015.09.015

Sanz, M. A., Fenaux, P., Tallman, M. S., Estey, E. H., Lowenberg, B., Naoe, T., et al. (2019). Management of acute promyelocytic leukemia: updated recommendations from an expert panel of the European LeukemiaNet. Blood 133, 1630-1643. doi: 10.1182/blood-2019-01-894980

Selmani, Z., Naji, A., Zidi, I., Favier, B., Gaiffe, E., Obert, L., et al. (2010). Human leukocyte antigen-G5 secretion by human mesenchymal stem cells is required to suppress $\mathrm{T}$ lymphocyte and natural killer function and to induce CD4+CD25highFOXP3+ regulatory T cells. Stem Cells 26, 212-222. doi: 10. 1634/stemcells.2007-0554

Shen, C., Yang, C., Xu, S., and Zhao, H. (2019). Comparison of osteogenic differentiation capacity in mesenchymal stem cells derived from human amniotic membrane (AM), umbilical cord (UC), chorionic membrane (CM), and decidua (DC). Cell Biosci. 9:17. doi: 10.1186/s13578-019-0281-3

Shou, P., Chen, Q., Jiang, J., Xu, C., Zhang, J., Zheng, C., et al. (2016). Type I interferons exert anti-tumor effect via reversing immunosuppression mediated by mesenchymal stromal cells. Oncogene 35, 5953-5962. doi: 10.1038/onc.20 16.128

Song, Y., Lim, J. Y., Lim, T., Im, K. I., Kim, N., Nam, Y. S., et al. (2020). Human mesenchymal stem cells derived from umbilical cord and bone marrow exert 
immunomodulatory effects in different mechanisms. World J. Stem Cells 12, 1032-1049. doi: 10.4252/wjsc.v12.i9.1032

Stefanska, K., Ozegowska, K., Hutchings, G., Popis, M., Moncrieff, L., Dompe, C., et al. (2020). Human Wharton's Jelly-cellular specificity, stemness potency, animal models, and current application in human clinical trials. J. Clin. Med. 9:1102. doi: 10.3390/jcm9041102

Subramanian, A., Fong, C. Y., Biswas, A., and Bongso, A. (2015). Comparative characterization of cells from the various compartments of the human umbilical cord shows that the Wharton's Jelly compartment provides the best source of clinically utilizable mesenchymal stem cells. PLoS One 10:e0127992. doi: 10.1371/journal.pone.0127992

Szaraz, P., Librach, M., Maghen, L., Iqbal, F., Barretto, T. A., Kenigsberg, S., et al. (2016). In vitro differentiation of first trimester human umbilical cord perivascular cells into contracting Cardiomyocyte-like cells. Stem Cells Int. 2016:7513252. doi: 10.1155/2016/7513252

Testa, U., Pelosi, E., and Castelli, G. (2019). CD123 as a therapeutic target in the treatment of hematological malignancies. Cancers 11:1358. doi: 10.3390/ cancers 11091358

Thaweesapphithak, S., Tantrawatpan, C., Kheolamai, P., Tantikanlayaporn, D., Roytrakul, S., and Manochantr, S. (2019). Human serum enhances the proliferative capacity and immunomodulatory property of MSCs derived from human placenta and umbilical cord. Stem Cell Res. Ther. 10:79. doi: 10.1186/ s13287-019-1175-3

Tian, K., Yang, S., Ren, Q., Han, Z., Lu, S., Ma, F., et al. (2010). p38 MAPK contributes to the growth inhibition of leukemic tumor cells mediated by human umbilical cord mesenchymal stem cells. Cell. Physiol. 26, 799-808. doi: $10.1159 / 000323973$

Tinazzi, E., Osti, N., Beri, R., Argentino, G., Veneri, D., Dima, F., et al. (2020). Pathogenesis of immune thrombocytopenia in common variable immunodeficiency. Autoimmun. Rev. 19:102616. doi: 10.1016/j.autrev.2020. 102616

van der Pouw Kraan, T. C., Boeije, L. C., Smeenk, R. J., Wijdenes, J., and Aarden, L. A. (1995). Prostaglandin-E2 is a potent inhibitor of human interleukin 12 production. J. Exp. Med. 181, 775-779. doi: 10.1084/jem.181.2.775

Van Pham, P., Thi-My Nguyen, P., Thai-Quynh Nguyen, A., Minh Pham, V., Nguyen-Tu Bui, A., Thi-Tung Dang, L., et al. (2014). Improved differentiation of umbilical cord blood-derived mesenchymal stem cells into insulin-producing cells by PDX-1 mRNA transfection. Differentiation 87, 200-208. doi: 10.1016/j. diff.2014.08.001

Wang, D., Huang, S., Yuan, X., Liang, J., Xu, R., Yao, G., et al. (2017). The regulation of the Treg/Th17 balance by mesenchymal stem cells in human systemic lupus erythematosus. Cell Mol. Immunol. 14, 423-431. doi: 10.1038/cmi. 2015.89

Wang, H., Qiu, X., Ping, N. I., Qiu, X., Lin, X., Weizhao, W. U., et al. (2014). Immunological characteristics of human umbilical cord mesenchymal stem cells and the therapeutic effects of their transplantion on hyperglycemia in diabetic rats. Intern. J. Mol. Med. 33, 263-270. doi: 10.3892/ijmm.2013. 1572

Wang, L., Gu, Z., Zhao, X., Yang, N., Wang, F., Deng, A., et al. (2016). Extracellular vesicles released from human umbilical cord-derived Mesenchymal stromal cells prevent life-threatening acute graft-versus-host disease in a mouse model of allogeneic hematopoietic stem cell transplantation. Stem Cells Dev. 25, 1874-1883. doi: 10.1089/scd.2016.0107

Wang, W., Li, L., Chen, F., and Yang, Y. (2018). Umbilical cordderived mesenchymal stem cells can inhibit the biological functions of melanoma A375 cells. Oncol. Rep. 40, 511-517. doi: 10.3892/or.2018.6446

Wang, X., Yin, X., Sun, W., Bai, J., Shen, Y., Ao, Q., et al. (2017). Intravenous infusion umbilical cord-derived mesenchymal stem cell in primary immune thrombocytopenia: a two-year follow-up. Exp. Ther. Med. 13, 2255-2258. doi: 10.3892/etm.2017.4229

Wang, Z. G., He, Z. Y., Liang, S., Yang, Q., Cheng, P., and Chen, A. M. (2020). Comprehensive proteomic analysis of exosomes derived from human bone marrow, adipose tissue, and umbilical cord mesenchymal stem cells. Stem Cell Res. Ther. 11:511. doi: 10.1186/s13287-020-02032-8

Watson, N., Divers, R., Kedar, R., Mehindru, A., Mehindru, A., Borlongan, M. C., et al. (2015). Discarded Wharton jelly of the human umbilical cord: a viable source for mesenchymal stromal cells. Cytotherapy 17, 18-24. doi: 10.1016/j. jcyt.2014.08.009
Wu, K. H., Chan, C. K., Tsai, C., Chang, Y. H., Sieber, M., Chiu, T. H., et al. (2011). Effective treatment of severe steroid-resistant acute graft-versus-host disease with umbilical cord-derived mesenchymal stem cells. Transplantation 91:1412. doi: 10.1097/tp.0b013e31821aba18

Wu, K. H., Tsai, C., Wu, H. P., Sieber, M., Peng, C. T., and Chao, Y. H. (2013). Human application of ex vivo expanded umbilical cord-derived mesenchymal stem cells: enhance hematopoiesis after cord blood transplantation. Cell Transpl. 22, 2041-2051. doi: 10.3727/096368912x663533

Wu, K. H., Wang, S. Y., Xiao, Q. R., Yang, Y., Huang, N. P., Mo, X. M., et al. (2018). Efficient generation of functional cardiomyocytes from human umbilical cordderived virus-free induced pluripotent stem cells. Cell Tissue Res. 374, 275-283. doi: 10.1007/s00441-018-2875-1

Wu, Y., Cao, Y., Li, X., Xu, L., Wang, Z., Liu, P., et al. (2014). Cotransplantation of haploidentical hematopoietic and umbilical cord mesenchymal stem cells for severe aplastic anemia: successful engraftment and mild GVHD. Stem Cell Res. 12, 132-138. doi: 10.1016/j.scr.2013.10.001

Wu, Y., Wang, Z., Cao, Y., Xu, L., Li, X., Liu, P., et al. (2013). Cotransplantation of haploidentical hematopoietic and umbilical cord mesenchymal stem cells with a myeloablative regimen for refractory/relapsed hematologic malignancy. Ann. Hematol. 92, 1675-1684. doi: 10.1007/s00277-013-1831-0

Xie, Q., Liu, R., Jiang, J., Peng, J., Yang, C., Zhang, W., et al. (2020). What is the impact of human umbilical cord mesenchymal stem cell transplantation on clinical treatment? Stem Cell Res. Ther. 11:519. doi: 10.1186/s13287-02002011-z

Xu, L., Liu, Z., Wu, Y., Yang, X., Cao, Y., Li, X., et al. (2018). Clinical evaluation of haploidentical hematopoietic combined with human umbilical cord-derived mesenchymal stem cells in severe aplastic anemia. Eur. J. Med. Res. 23:12. doi: 10.1186/s40001-018-0311-3

Xue, Z. L., Meng, Y. L., and Ge, J. H. (2018). Upregulation of miR-132 attenuates osteoblast differentiation of UC-MSCs. Eur. Rev. Med. Pharmacol. Sci. 22, 1580-1587. doi: 10.26355/eurrev_201803_14562

Yan, C., Li, S., Li, Z., Peng, H., Yuan, X., Jiang, L., et al. (2013). Human umbilical cord mesenchymal stem cells as vehicles of CD20-specific TRAIL fusion protein delivery: a double-target therapy against non-Hodgkin's lymphoma. Mol. Pharm. 10, 142-151. doi: 10.1021/mp300261e

Yang, H., Sun, J., Yan, L., Duan, W. M., Bi, J., and Qu, T. (2016). Human umbilical cord-derived mesenchymal stem cells suppress proliferation of PHA-activated lymphocytes in vitro by inducing CD $4+$ CD25 high CD45RA + regulatory $\mathrm{T}$ cell production and modulating cytokine secretion. Cell. Immunol. 302, 26-31. doi: 10.1016/j.cellimm.2016.01.002

Yang, S., Wei, Y., Sun, R., Lu, W., Lv, H., Xiao, X., et al. (2020). Umbilical cord blood-derived mesenchymal stromal cells promote myeloid-derived suppressor cell proliferation by secreting HLA-G to reduce acute graft-versus-host disease after hematopoietic stem cell transplantation. Cytotherapy 22, 718-733. doi: 10.1016/j.jcyt.2020.07.008

Yang, Z. X., Chi, Y., Ji, Y. R., Wang, Y. W., Zhang, J., Luo, W. F., et al. (2017). Human umbilical cord mesenchymal stem cells increase interleukin-9 production of CD4(+) T cells. Exp. Ther. Med. 14, 3541-3548. doi: 10.3892/ etm.2017.4952

Yea, J. H., Bae, T. S., Kim, B. J., Cho, Y. W., and Jo, C. H. (2020). Regeneration of the rotator cuff tendon-to-bone interface using umbilical cord-derived mesenchymal stem cells and gradient extracellular matrix scaffolds from adipose tissue in a rat model. Acta Biomater. 114, 104-116. doi: 10.1016/j.actbio. 2020.07.020

Young, N. S. (2018). Aplastic anemia. N. Engl. J. Med. 379, 1643-1656. doi: 10.1056/ NEJMra1413485

Yuan, L., Liu, Y., Qu, Y., Liu, L., and Li, H. (2019). Exosomes derived From MicroRNA-148b-3p-overexpressing human umbilical cord mesenchymal stem cells restrain breast cancer progression. Front. Oncol. 9:1076. doi: 10.3389/fonc. 2019.01076

Yuan, X., Qin, X., Wang, D., Zhang, Z., Tang, X., Gao, X., et al. (2019). Mesenchymal stem cell therapy induces FLT3L and CD1c(+) dendritic cells in systemic lupus erythematosus patients. Nat. Commun. 10:2498. doi: 10.1038/ s41467-019-10491-8

Yuan, Y., Zhou, C., Chen, X., Tao, C., Cheng, H., and Lu, X. (2018). Suppression of tumor cell proliferation and migration by human umbilical cord mesenchymal stem cells: a possible role for apoptosis and Wnt signaling. Oncol. Lett. 15, 8536-8544. doi: 10.3892/ol.2018.8368 
Shang et al.

UC-MSC in Hematological Disorders

Chan, X. S., El-Ashram, S., Luo, D. Z., Luo, H. N., Wang, B. Y., Chen, S. F., et al. (2019). A Comparative study of biological characteristics and transcriptome profiles of mesenchymal stem cells from different canine tissues. Int. J. Mol. Sci. 20:1485. do: 10.3390/ijms20061485

Chang, H., Tao, Y., Lu, H., Ken, S., Zhang, B., and Chen, H. (2017). Immunomodulatory function of whole human umbilical cord derived mesenchymal stem cells. Mol. Immunol. 87, 293-299. do: 10.1016/j.molimm. 2017.03.003

Chang, X., Yang, Y., Zhang, L., Lu, Y., Zhang, Q., Fan, D., et al. (2017). Mesenchymal stromal cells as vehicles of tetravalent bispecific Tandab (CD3/CD19) for the treatment of B cell lymphoma combined with IDO pathway inhibitor D-1-methyl-tryptophan. J. Hematol. Oncol. 10:56. dor: 10. 1186/s13045-017-0397-z

Zhang, Y., Zhu, Z., Hua, K., Yo, L., Lu, Y., and Ding, J. (2018). Umbilical cordderived mesenchymal stem cell transplantation in vaginal replacement in vito and in a rat model. Am. J. Transl. Res. 10, 3762-3772.

Chang, Z., Huang, S., Wu, S., Qi, J., Li, W., Lu, S., et al. (2019). Clearance of apoptotic cells by mesenchymal stem cells contributes to immunosuppression via PGE2. eBro Med. 45, 341-350. dor: 10.1016/j.ebiom.2019.06.016

Zhao, L., Chen, S., Yang, P., Gao, H., and Li, L. (2019). The role of mesenchymal stem cells in hematopoietic stem cell transplantation: prevention and treatment of graft-versus-host disease. Stem Cell Res. There. 10:182. do: 10.1186/s13287019-1287-9

Chou, X., Gui, L., Zhou, X., Yang, Q., Wang, L., Gus, G., et al. (2017). Induction of hepatocyte-like cells from human umbilical cord-derived mesenchymal stem cells by defined microRNAs. J. Cell Mol. Med. 21, 881-893. do: 10.1111/jcmm. 13027

Chou, X., Li, T., Chen, Y., Chang, N., Wang, P., Liang, Y., et al. (2019). Mesenchymal stem cellderived extracellular vesicles promote the in vito proliferation and migration of breast cancer cells through the activation of the ERK pathway. Int. J. Oncol. 54, 1843-1852. doa: 10.3892/ijo.2019.4747

Conflict of Interest: The authors declare that the research was conducted in the absence of any commercial or financial relationships that could be construed as a potential conflict of interest.

Copyright (c) 2021 Shang, Guan and Chou. This is an open-access article distributed under the terms of the Creative Commons Attribution License (CC BY). The use, distribution or reproduction in other forums is permitted, provided the original authors) and the copyright owners) are credited and that the original publication in this journal is cited, in accordance with accepted academic practice. No use, distribution or reproduction is permitted which does not comply with these terms.

Frontiers in Cell and Developmental Biology | www.frontiersin.org

11

May 2021 | Volume 9 | Article 570179 